$[\mathrm{U}-\mathrm{Cd}=4.17 \mu \mathrm{g} / \mathrm{g} \mathrm{Cr}$ ] and highly [U-Cd $=11.39 \mu \mathrm{g} / \mathrm{g} \mathrm{Cr}$ ] polluted areas). B-Cd, U-Cd concentrations were measured by graphite-furnace atomic absorption spectrometry. Polymorphisms in MT2A (rs10636 G/C, rs1610216 C/T and rs28366003 A/G) were determined by Taqman assays. Urinary $\mathrm{N}$-Acetyl-beta-(D)-Glucosaminidase (UNAG) was determined by spectrometry, urinary $\beta 2$-microglobulin (UB2M) and albumin (UALB) by ELISA.

Results BCd and UCd had an association with variant alleles for MT2A (rs10636) in female living in the highly polluted group ( $p$ $=0.017$ and 0.004 , respectively). UCd had a weak association with variant alleles for MT2A (rs28366003) in the highly polluted group $(\mathrm{p}=0.08$, ). An association wasn't found between renal dysfunction and MT2A polymorphisms variation in polluted group.

Conclusions The finding indicates genetic variation in the MT2A genes may not associate with renal dysfunction caused by cadmium exposure.

\section{HAND ECZEMA IN THE CONSTRUCTION INDUSTRY: PREVALENCE AND DETERMINANTS}

J G Timmerman, Heederik, Spee, Smit. Institute for Risk Assessment Sciences (Utrecht University), Utrecht, Nederland

\subsection{6/oemed-2013-101717.121}

Introduction In most Western European countries, prevalence of hand eczema in the general population is estimated at around $4 \%$. In the construction industry, a higher prevalence can be expected due to exposure to irritating and allergenic agents. Aim of the present study was to investigate the prevalence and determinants of hand eczema in several job titles within the construction industry.

Methods As part of a voluntary medical examination, a questionnaire including items on health symptoms and working circumstances was administered to construction workers between 2005 and 2011. A response rate of about 50\% was achieved, 152.200 men were included: 115.379 construction yard workers and 36.821 office personnel. Hand eczema was defined as one or more self-reported skin symptoms. Associations between possible risk factors and hand eczema were assessed using log-binomial regression.

Results Hand eczema prevalence was 25\% among construction yard personnel and 15\% among office personnel. Skin hypersensitivity for job-related substances was reported by $10 \%$ and $3 \%$, respectively. Hand eczema was most often reported by plasterers $(36 \%)$ and bricklayers (31\%). Carpenters and painters most frequently reported skin hypersensitivity (both 11\%). Compared to office personnel, all construction yard job titles had a significantly increased prevalence ratio (PR) for hand eczema. Among construction yard personnel, dry skin (PR 2.02, 95\% confidence interval (CI): 1.95-2.10) and nuisance due to exposure to dust (PR: 1.57, 95\% CI: 1.53-1.61) were the most important determinants for hand eczema. For skin hypersensitivity, dry skin (PR 2.27, 95\% CI: 2.19-2.36) and dust exposure (PR 1.78, 95\% CI: 1.71-1.86) were also the main determinants. Skin hypersensitivity was reported less often among glove users (PR 0.61, 95\% CI: $0.58-0.63$ ).

Conclusion Hand eczema is very common among construction workers. Dust exposure and a dry skin type were associated with a higher prevalence of hand eczema and work-related skin hypersensitivity.

\section{ABSENTEEISM BY CONJUNCTIVITIS AND DERMATITIS HEALTH CARE IN PROFESSIONALS WHO USE LATEX AT A UNIVERSITY HOSPITAL IN SĆO PAULO, BRAZIL}

E.C.S. Sá, Campos, Piovesan, Pustiglione. Faculdade de Medicina da Universidade de Sāo Paulo, Sāo Paulo, Brazil

\subsection{6/oemed-2013-101717.122}

Objectives To evaluate absenteeism in health care professionals that showed removal by conjunctivitis and contact dermatitis from the latex during the period September, 2011 to September, 2012 at a university hospital in São Paulo, Brazil.

Methods We performed a study about the absenteeism among health professionals of university hospital in São Paulo, from September 1, 2011 to September 30, 2012, with workers who have had absences related to conjunctivitis and dermatitis contact. Moreover, were consulted scientific databases (MEDLINE via PubMed, LILACS, SciELO) between October 1 and November 20, 2012, restricting the articles in English, Portuguese or Spanish, published between 1990 and 2011.

Results There was 96 workers diagnosed with contact dermatitis and 1331 workers with conjunctivitis. In the sample, were identified eleven staff who had both diagnoses of conjunctivitis and contact dermatitis: 05 were workers from various areas of the hospital and 06 were health professionals, such as: 01 laboratory technician, 01 nurse and 04 nursing technicians, who used latex gloves in their daily workday. There were 36 days of removal by conjunctivitis and contact dermatitis associated. This study showed the importance to research in different health institutions, aimed at earlier diagnosis related to latex allergy and to establish prevention campaigns, including the identification of the factors sensibilization in occupational health programs of the health care professionals.

Conclusion The study suggests the possibility of correlation between the both diagnosis of conjunctivitis and dermatitis to latex in healthcare professionals.

\section{OCCUPATIONAL CONTACT DERMATITIS: INITIAL AND SUBSEQUENT WORKERS' COMPENSATION CLAIMS IN VICTORIA, AUSTRALIA}

${ }^{1} \mathrm{G}$ Keegel, ${ }^{1}$ Benke, ${ }^{2}$ Nixon, ${ }^{1}$ Sim, ${ }^{3}$ LaMontagne. 'Monash University, Melbourne, Australia; ${ }^{2}$ Occupational Dermatitis Research and Education Centre, Skin \& Cancer Foundation, Melbourne, Australia; ${ }^{3}$ Melbourne School of Public Health, University of Melbourne, Melbourne, Australia

\subsection{6/oemed-2013-101717.123}

Objective Occupational contact dermatitis (OCD) is caused by a range of workplace exposures such as frequent hand-washing or exposure to irritating or allergic substances. We compare costs and days away from work for initial and subsequent workers' compensation claims for OCD amongst workers in Victoria, Australia.

Methods The Compensation Research Database (CRD), held by the Institute for Safety, Compensation and Recovery Research, contains de-identified details of all workers' compensation claims submitted to the Victorian WorkCover Authority. We accessed injury/disease, employment and demographic variables for OCD claims, as well as information about claim costs (in 2009 Australian dollar equivalent values) and days away from work, for the period January 1985-December 2009. The estimate for the 